\title{
Experience of Anticovid Plasma Procurement in the Sakha Republic (Yakutia)
}

\author{
A.N. Evseev ${ }^{1}$, A.R. Ermolaev ${ }^{1, *}$, N.V. Savvina ${ }^{1}$ and V.V. Gerasimova ${ }^{1}$ \\ ${ }^{1}$ M.K. Ammosov North-Eastern federal university \\ *Corresponding author. Email: ar.ermolayev@s-vfu.ru
}

\begin{abstract}
Anticoid plasma transfusion (AP) is considered to be one of the for COVID-19 treatment. The retrospective study included 73 COVID-19 convalescents who donated plasma of the Blood Transfusion Station in the Republic of Sakha (Yakutia) as potential AP donors. Donors who had a history of COVID-19 infection confirmed SARS-CoV-2 RNA in pharyngeal swabs by polymerase chain reaction method, availability of medical documentation, a period from the moment of the disease of at least 14 days were allowed to the plasma procurement procedure. The antibody titer was chosen as a characteristic of the immunological viability of AP. The characteristics of donors (gender, age) were compared with the antibody titer. The effective antibody titer (1: 800 and more) was found in $87.6 \%$ of donors, low titer (1: 200 and 1: 400) - in $12.4 \%$.
\end{abstract}

Keywords: anticovid plasma procurement,, COVID-19, antibody, Sakha Republic, Yakutia

\section{INTRODUCTION}

In March 2020, WHO declared a pandemic of a new infection caused by Coronaviridae virus: SARS - CoV2 family (Severe acute response syndrome coronavirus 2). The new coronavirus infection is called COVID-19. More than 13 million people have been infected in the world, over 570 thousand died [1]. COVID-19 is not the first coronavirus infection to occur in the world. In 2003, SARS epidemic caused by the SARS-CoV virus took place, and in 2012 - MERS [2]. One of the effective approaches was transfusion of blood plasma of recovered patients (reconvalescent plasma) in the period of past epidemics, without specific treatment. Treatment with plasma transfusions obtained from reconvalescents is passive immunization by administering antibodies to the infectious agent. Such a treatment has a long history, starting with the Spanish pandemic more than 100 years ago [2-7]. The efficacy of reconvalescent plasma transfusion was also shown in the 2009 influenza H1N1 epidemic [4].

There is no etiotropic therapy of COVID-19 with proven effectiveness. The high lethality associated with COVID-19 demanded urgent decisions, and by analogy with the previous infections caused by coronavirus, the groups of experts from the different countries came to a conclusion about expediency of plasma use of convalescents (convalescent plasma, or reconvalestsent plasma, or, according to "The temporary recommendations of Ministry of Health of the Russian Federation" (version 6), is applied anti-covid pathogenreduced plasma - CPP) for COVID-19 patients [8-9]. A number of countries have developed programs for AP clinical use [8-9]. The main parameter providing therapeutic efficacy of the reconvalescent plasma is its presence and titer of antibodies. At the same time, researches show that the severity of the immune response to COVID-19 is different, and antibodies are not determined in all patients [10]. In this regard, careful selection of reconvalescent donors is relevant when producing plasma with high therapeutic efficacy.

The purpose of the research is to study quantitative content of antibodies in fresh frozen plasma of reconvalescents.

\section{MATERIALS AND METHODS}

According to the order of the Ministry of Health of the Sakha (Yakutia) Republic of August 04, 2020 No. 01-07/1061 "About the organization work order on 
preparation, examination, storage, transportation and safety of fresh frozen plasma from donor convalescents of COVID-19 and its use", and began preparation of plasma from COVID-19 reconvaletsent on the basis of State Budgetary Institution (Yakutia). The criteria for donor selection were the infection COVID-19 confirmed by polymerase chain reaction detection (PCR) of RNA SARS-CoV-2 in swabs from the pharynx, medical documentation indicating two negative results and the period from the moment of discharge from the hospital for at least 14 days.

The article summarizes the results of studies for the period from August to December 2020, tested 73 samples from potential donors, the average age of donors was 41 years old.

Serological researches were conducted in laboratory of immunological researches with use of the immunoenzymatic analysis, implementation of tests was carried out by the registered test system VektorBest SARS-CoV-2 IgG - IFA-Best. All studies were performed according to the instructions of the manufacturer.

Blood test for antibody titer was performed directly before the donor plasmophoresis, and the titer's dependence on age, sex and time on antibody appearance and regression was evaluated.

\section{RESULTS AND DISCUSSIONS}

A high titer of antibodies to the $\operatorname{IgG}$ of coronavirus infection (1:800 or more) was detected in $64(88 \%)$ donors, a low titer $(1: 400)$ - in $9(12 \%)$. The distribution of plasma donors depending on antibody titer is shown in Figure 1.

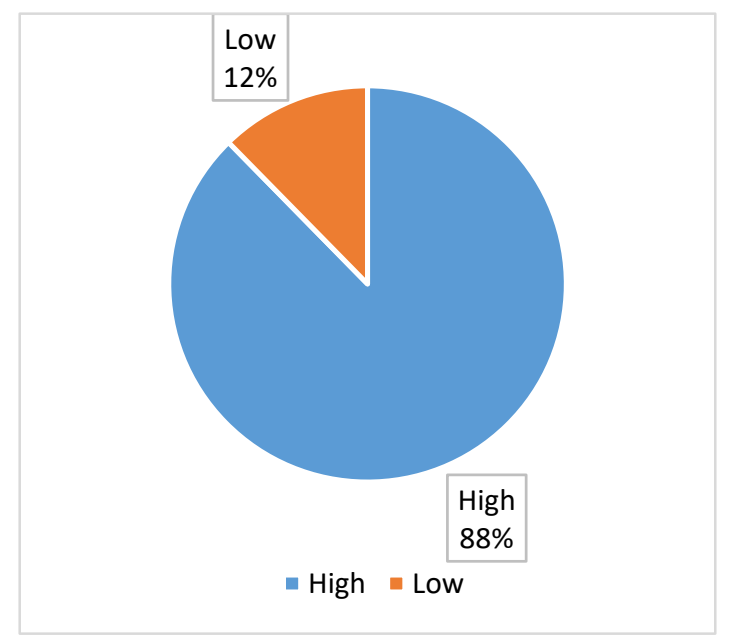

Figure 1. Distribution of donors according to antibody titer in blood plasma
There were 32 men (44\%) and 41 women (56\%) among donors (fig. 2).

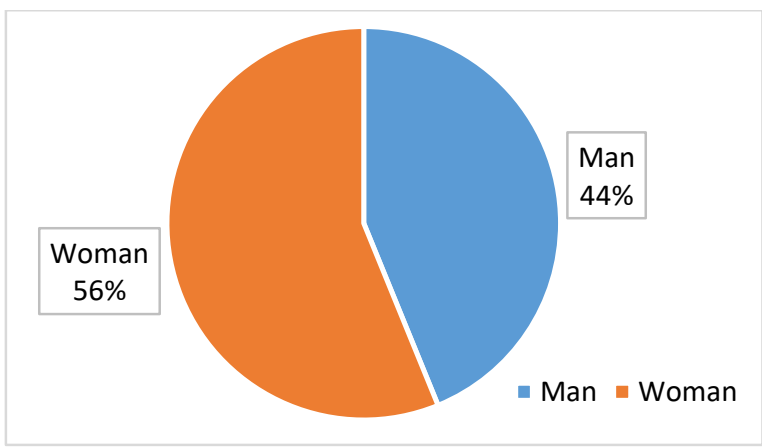

Figure 2. Gender distribution of donors

More men aged 40-49 years old were at the consultation (fig. 3).

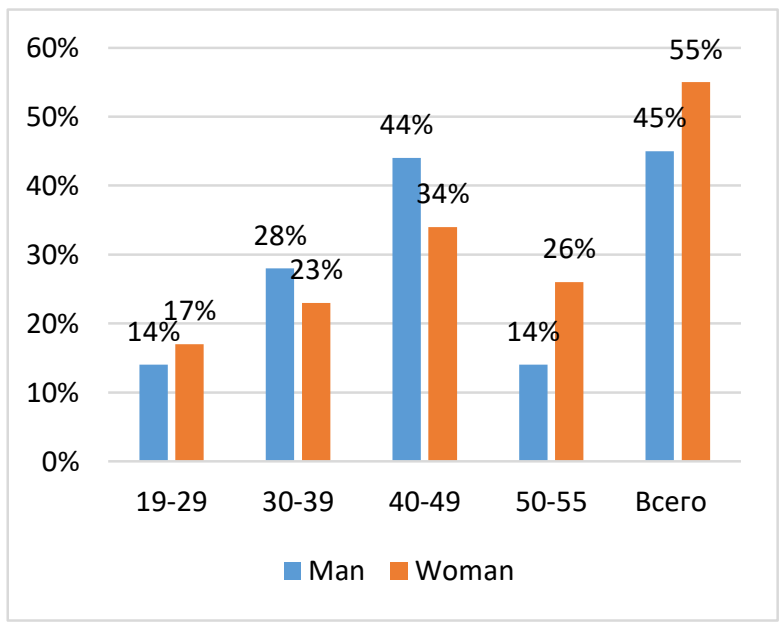

Figure 3. People at the consultation

Donors with the first and second blood types (fig. 4)

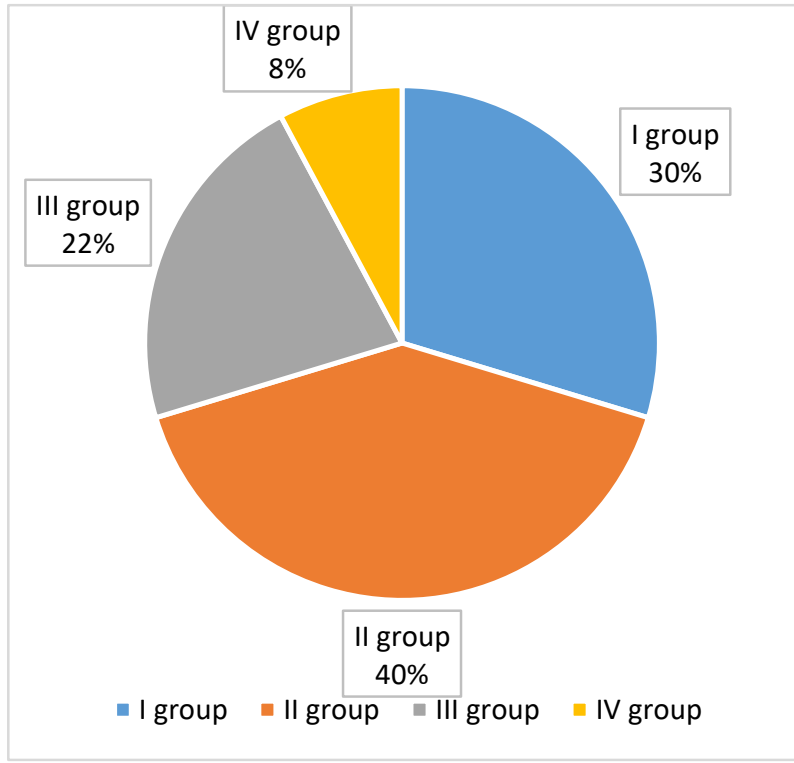

Figure 4. Donors with the first and second blood types 
Female donors prevailedw with blood type 1 and 2, men - blood type 3 and 4 (fig. 5).

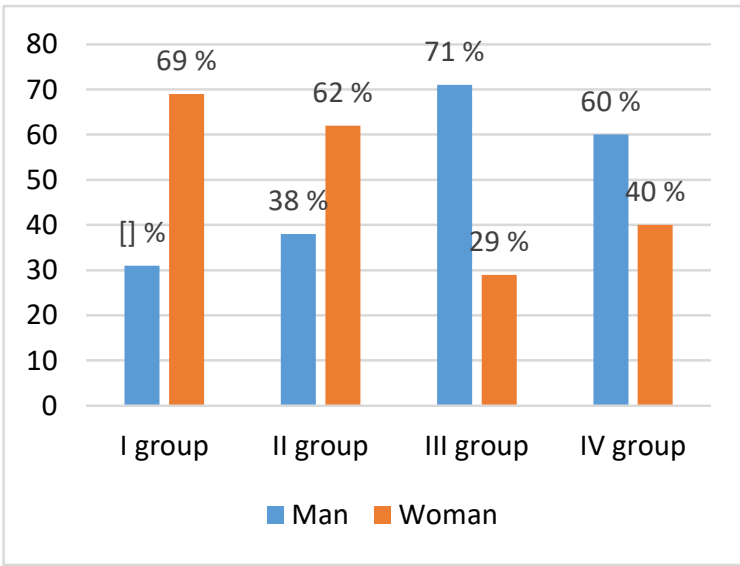

Figure 5. Distribution of donors by blood group

The ratio was as follows according to social status: employees $-82 \%$, workers $-18 \%$ (fig. 6).

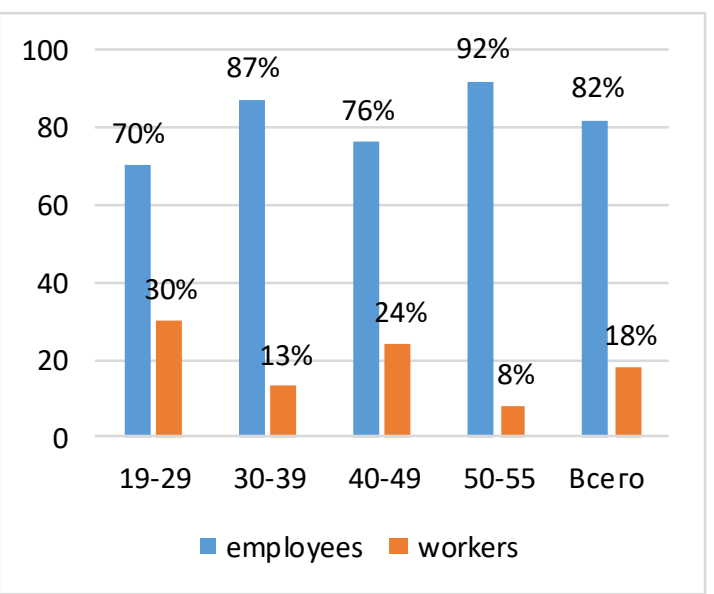

Figure 6. Social status of donors

There is an antibody titer increase after 4 weeks in the middle age group (40-49 years old), and the remaining titers were preserved or decreased (Table 1).

Table 1. Antibody titer dynamics

Antibody titer dynamics

\begin{tabular}{|l|l|l|l|l|l|}
\hline Donor & Age & Gender & 1 donation & 2 donation & Note \\
\hline Donor D & $30-39$ & male & $1: 12800$ & $1: 6400$ & Decline in 10 weeks. \\
\hline Donor L & $40-49$ & female & $1: 800$ & $1: 800$ & titer are saved in 2 weeks. \\
\hline Donor N & $50-55$ & female & $1: 3200$ & $1: 800$ & Decline in 7 weeks. \\
\hline Donor V & $50-55$ & female & $1: 3200$ & $1: 1600$ & Decline in 17 weeks. \\
\hline Donor T & $40-49$ & female & $1: 3200$ & $1: 6400$ & Promotion in 4 weeks. \\
\hline Donor P & $30-39$ & male & $1: 6400$ & $1: 3200$ & Antibody titer reduction in 8 weeks \\
\hline Donor Z & $40-49$ & male & $1: 800$ & $1: 800$ & Saved in 3 weeks. \\
\hline Donor K & $40-49$ & male & $1: 800$ & $1: 800$ & Saved in 9 weeks. \\
\hline Donor A & $50-55$ & male & $1: 800$ & $1: 800$ & Saved in 2 weeks. \\
\hline Donor X & $50-55$ & female & $1: 6400$ & $1: 6400$ & Saved in 5 weeks. \\
\hline Donor C & $30-39$ & male & $1: 1600$ & $1: 800$ & Decline in 10 weeks. \\
\hline
\end{tabular}

\section{CONCLUSION}

As this research showed, the ideal candidates for recipients and donors were unknown. Experience had shown that antibodies in recovering patients were shortlived. Patients who had a severe course of disease might have adequate titers.

Thus, AP procurement from all COVID-19 reconvalescents, expressed the desire to be an immune plasma donor, was economically unprofitable due to the large immune non-effectiveness. Pre-testing for antibodies with the expectation of results for several days was also fraught with resource losses. Simple and accessible criteria needed to allow maximum selection of potentially effective donors at the early stage.

\section{REFERENCES}

[1] Worldometer Licensing is a provider of global COVID-19. Retrieved from: https://www.worldometers.info/coronavirus/

[2] T.C. Luke, E.M. Kilbane, J.L. Jackson, S.L. Hoffman, Meta-analysis: convalescent blood products for Spanish infl uenza pneumonia: a future H5N1 treatment, Ann. Intern. Med. 145(8) (2006) 599-609.

[3] J. Mair-Jenkins, M. Saavedra-Campos, J.K. Baillie et al., The effectiveness of convalescent plasma and hyperimmune immunoglobulin for the treatment of severe acute respiratory infections of 
viral etiology: a systematic review and exploratory meta-analysis, J. Infect. Dis. 211(1) (2015) 80-90.

[4] Y. Cheng, R. Wong, Y. Soo et al., Use of convalescent plasma therapy in SARS patients in Hong Kong, Eur. J. Clin. Microbiol. Infect. Dis. 24(1) (2015) 44-46.

[5] C. Drosten, S. Günther, W. Preiser et al., Identifi cation of a novel coronavirus in patients with severe acute respiratory syndrome, N. Engl. J. Med. 348 (2003) 1967-1976.

[6] A. Chafekar, B.C. Fielding, MERS-CoV: Understanding the latest human coronavirus threat, Viruses 10 (2008).

[7] Kuo-Ming Yeh, Tzong-Shi Chiueh, L.K. Siu et al., Experience of using convalescent plasma for severe acute respiratory syndrome among healthcare workers in a Taiwan hospital, J. Antimicrob. Chemother. 56(5) (2005) 919-922.

[8] C. Thompson, N., Grayson R. Paton, Neutralising antibodies to SARS coronavirus 2 in Scottish blood donors - a pilot study of the value of serology to determine population exposure, MedRxiv. (2020).

[9] Sh. Pei, X. Yuan, Z.Z. Zhang, Convalescent Plasma to Treat COVID-19: Chinese Strategy and Experiences, MedRxiv (2020).

[10] U.S. Food and Drug Administration. Recommendations for Investigational COVID-19 Convalescent Plasma (2020). 